Supplement of Web Ecol., 20, 133-141, 2020

https://doi.org/10.5194/we-20-133-2020-supplement

(C) Author(s) 2020. This work is distributed under

the Creative Commons Attribution 4.0 License.

(c) (i)

Supplement of

\title{
Feeding strategies differentiate four detritivorous curimatids in the Amazon
}

Thatyla Farago et al.

Correspondence to: Thatyla Farago (farago.thatyla@gmail.com)

The copyright of individual parts of the supplement might differ from the CC BY 4.0 License. 


\section{$\underline{\text { Tables }}$}

Table S1. Alimentary Index $\left(\mathrm{IA}_{\mathrm{i}}\right)(\%)$ of four species of Curimatidae. Detritus = degraded organic matter; Vegetal $=$ fragments of plant material; Microcrustaceans $=$ ostracods and snails; Microalgae $=$ chlorophytes and cyanophytes; Zooplankton $=$ cladocerans and copepods.

\begin{tabular}{|c|c|c|c|c|c|c|}
\hline \multicolumn{7}{|c|}{ Alimentary Index - IA $A_{\mathbf{i}}(\%)$} \\
\hline & Detritus & Vegetal & Microcrustaceans & Microalgae & Thecamoebians & Zooplankton \\
\hline P. latior & 99.87 & & & & & 0.13 \\
\hline P. altamazonica & 99.97 & & & 0.03 & & \\
\hline P. rutiloides & 99.45 & 0.002 & 0.051 & 0.006 & 0.001 & 0.49 \\
\hline P. amazonica & 100 & & & & & \\
\hline
\end{tabular}

Table S2. Percentage variation explained by the canonical axes (CVA) and the loadings for the size-corrected morphological traits. Explained proportion and significance values of each variable were tested on the first two CA axes using the envfit parametric test. Bold values indicate the more weighed variables in the first axis.

\begin{tabular}{lcccc}
\hline \multicolumn{1}{c}{ Trait } & CA1 & CA2 & $\mathbf{r}^{2}$ & $\boldsymbol{P}$ \\
\hline Intestine Weigth (IW) & 0.18 & -0.98 & 0.88 & 0.001 \\
Intestine Length (IL) & $\mathbf{0 . 8 3}$ & -0.56 & 0.87 & 0.001 \\
Total Length (TL) & $\mathbf{- 0 . 7 5}$ & 0.67 & 0.10 & 0.001 \\
Total Weight (TW) & $\mathbf{0 . 9 5}$ & 0.32 & 0.57 & 0.001 \\
Somatic Digestive Index (DSI) & -0.13 & -0.99 & 0.98 & 0.001 \\
\hline Explained variation (\%) & 88.9 & 7.4 & & \\
\hline
\end{tabular}




\section{Figures}
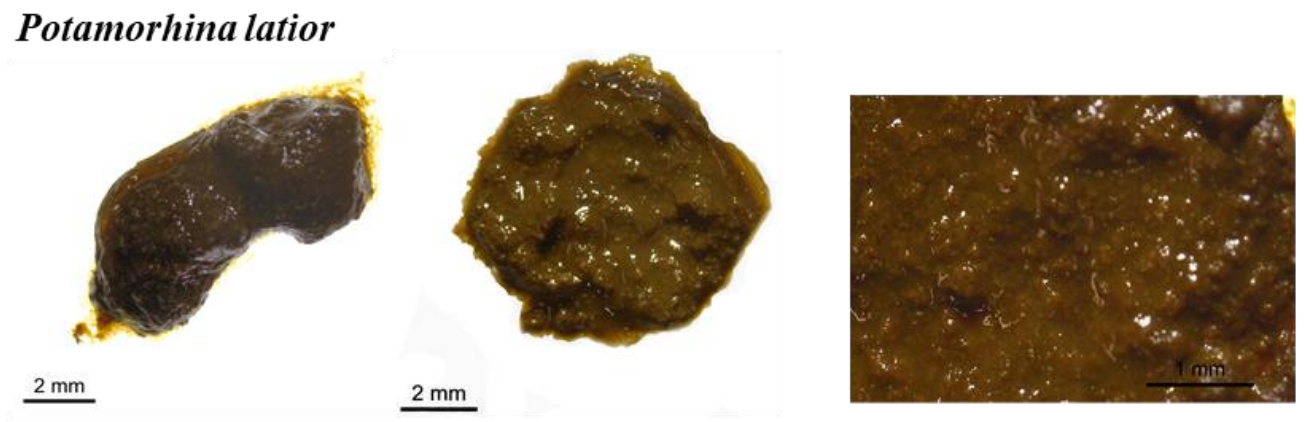

\section{Potamorhina altamazonica}
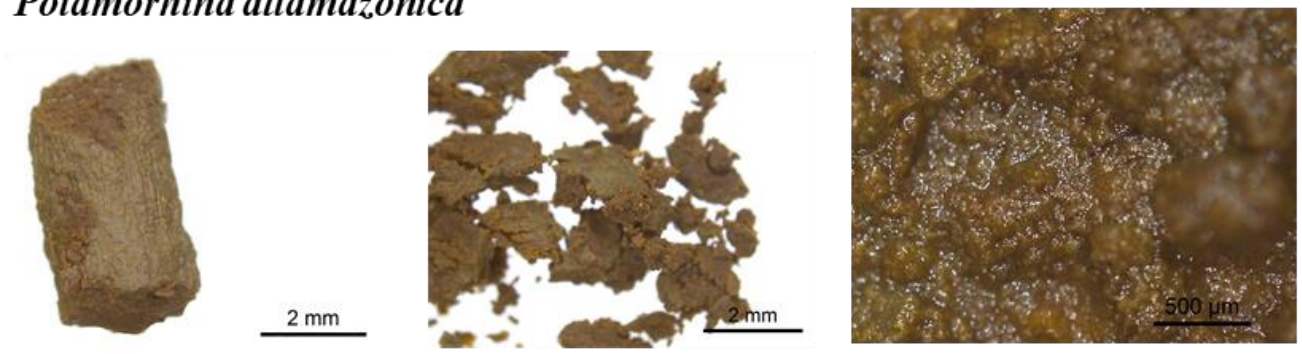

\section{Psectrogaster rutiloides}
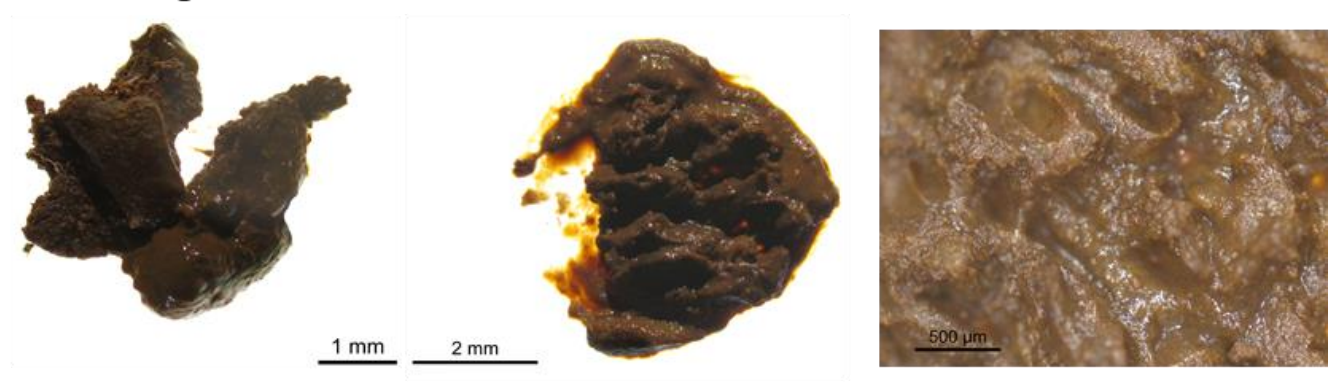

Psectrogaster amazonica
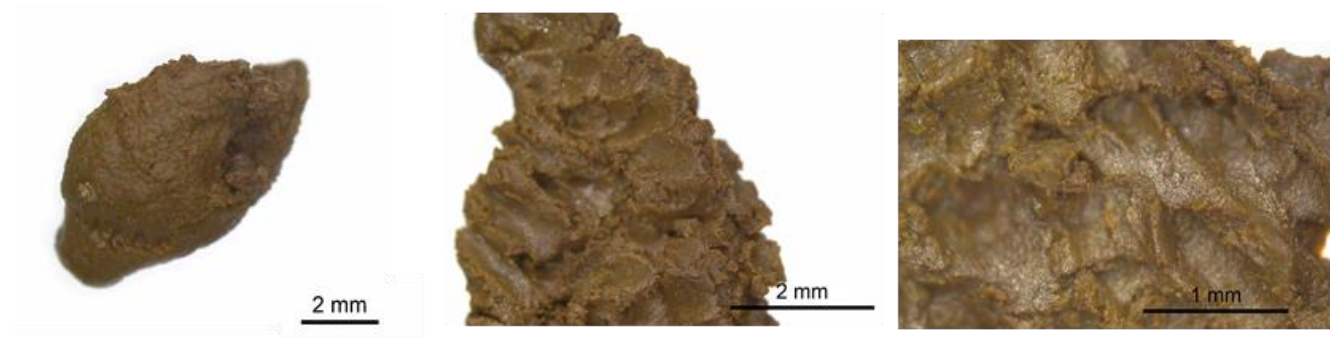

Figure S1. Stomach content of Potamorhina latior, Potamorhina altamazonica, Psectrogaster rutiloides and Psectrogaster amazonica. Images made with stereomicroscope Leica S9i. 

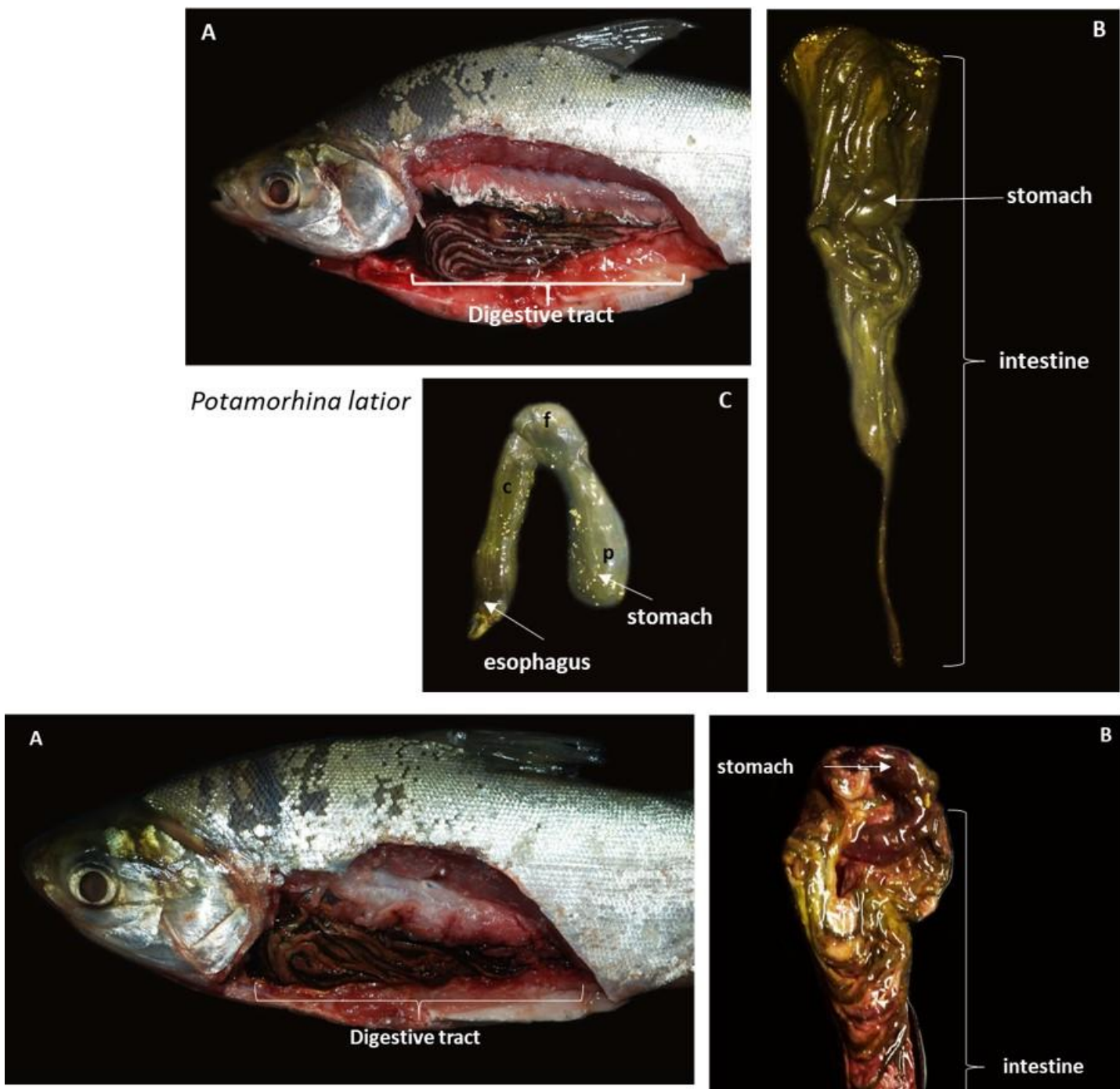

Potamorhina altamazonica
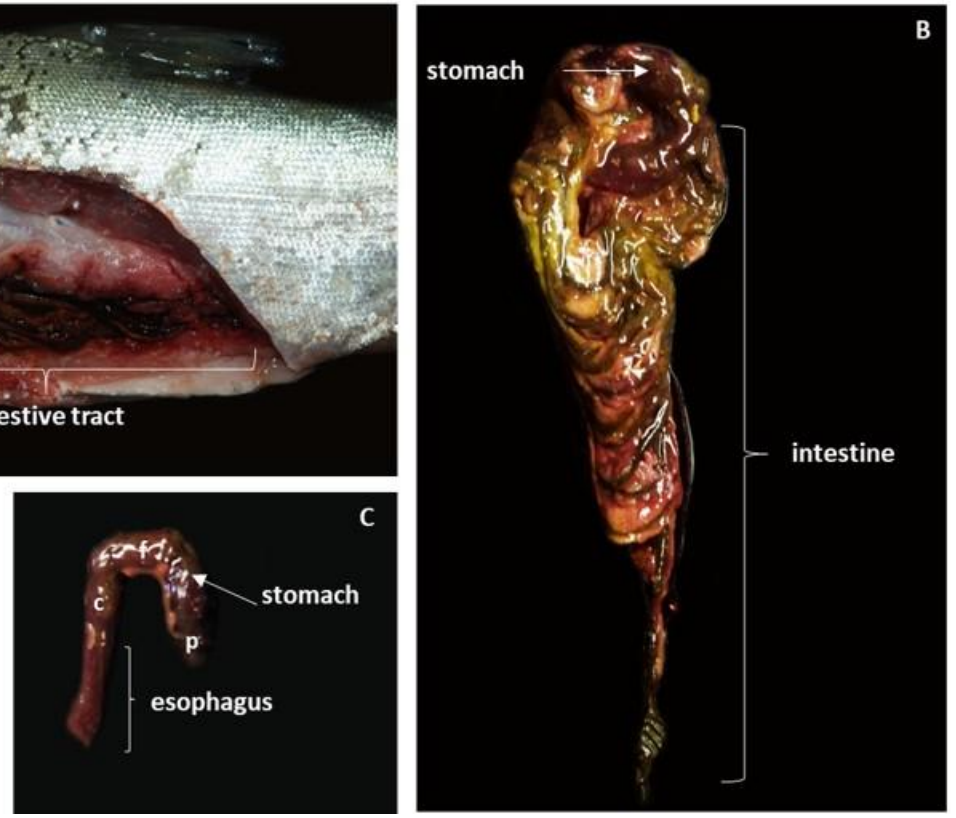

Figure S2. Images of the digestive tract of Potamorhina latior $(81 \mathrm{~mm})$ and Potamorhina altamazonica $(175 \mathrm{~mm})$. A: General view of the celom cavity indicating the position of the digestive tract. B: Digestive tract indicating stomach and long coiled intestine. C: Small, elongated stomach, of the fundic type with pyloric (p), fundic (f) and cardiac (c) regions, and esophagus. 


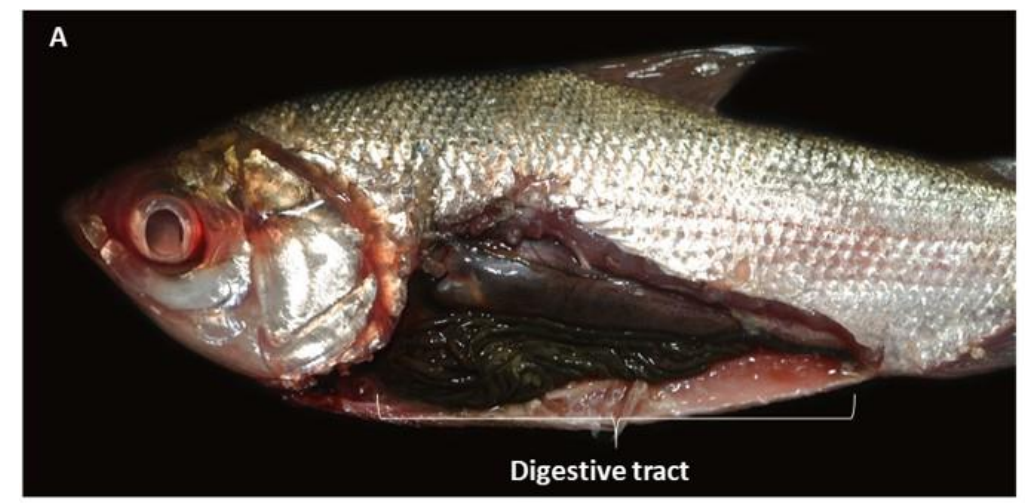

Psectrogaster rutiloides
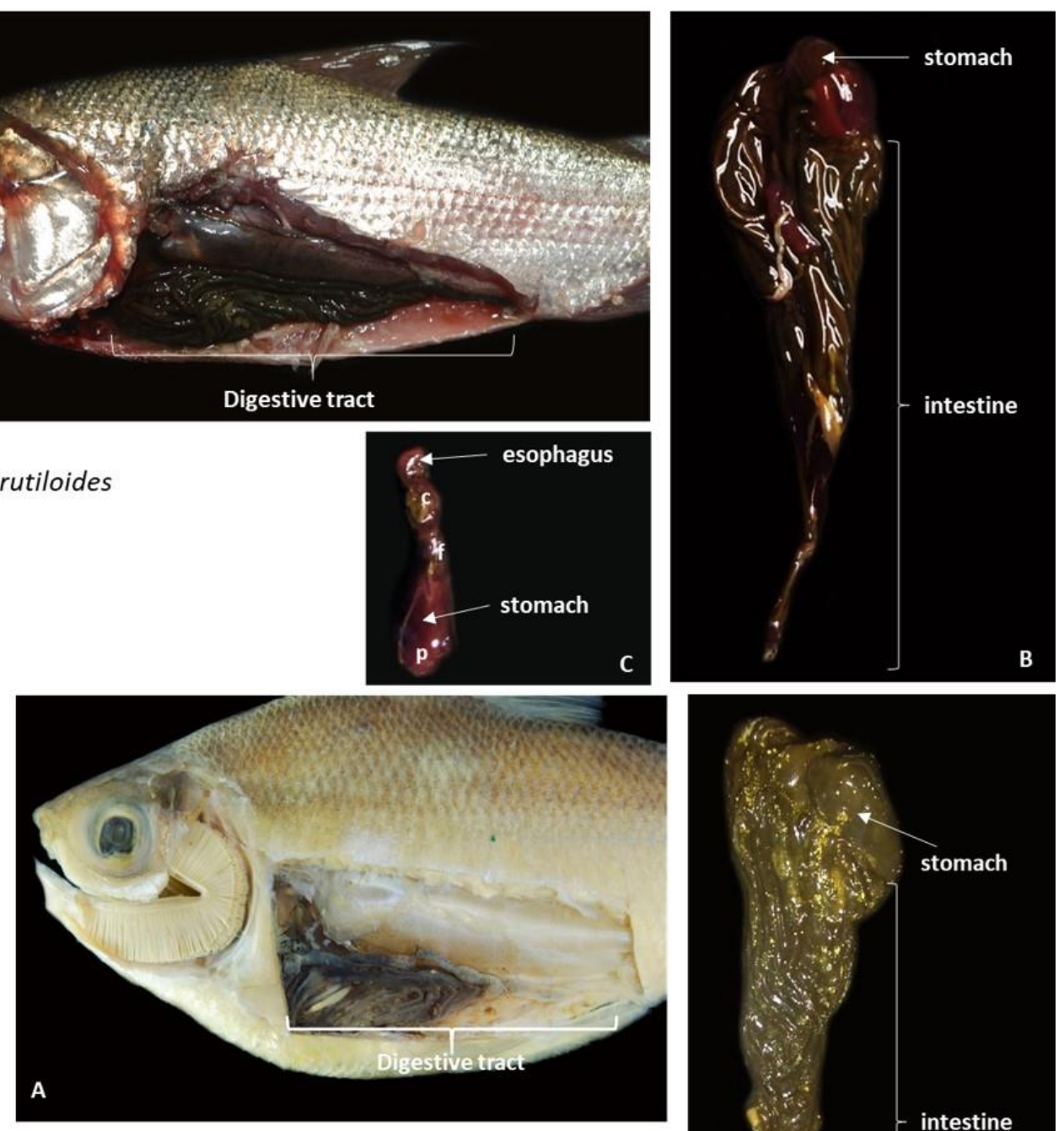

Psectrogaster amazonica
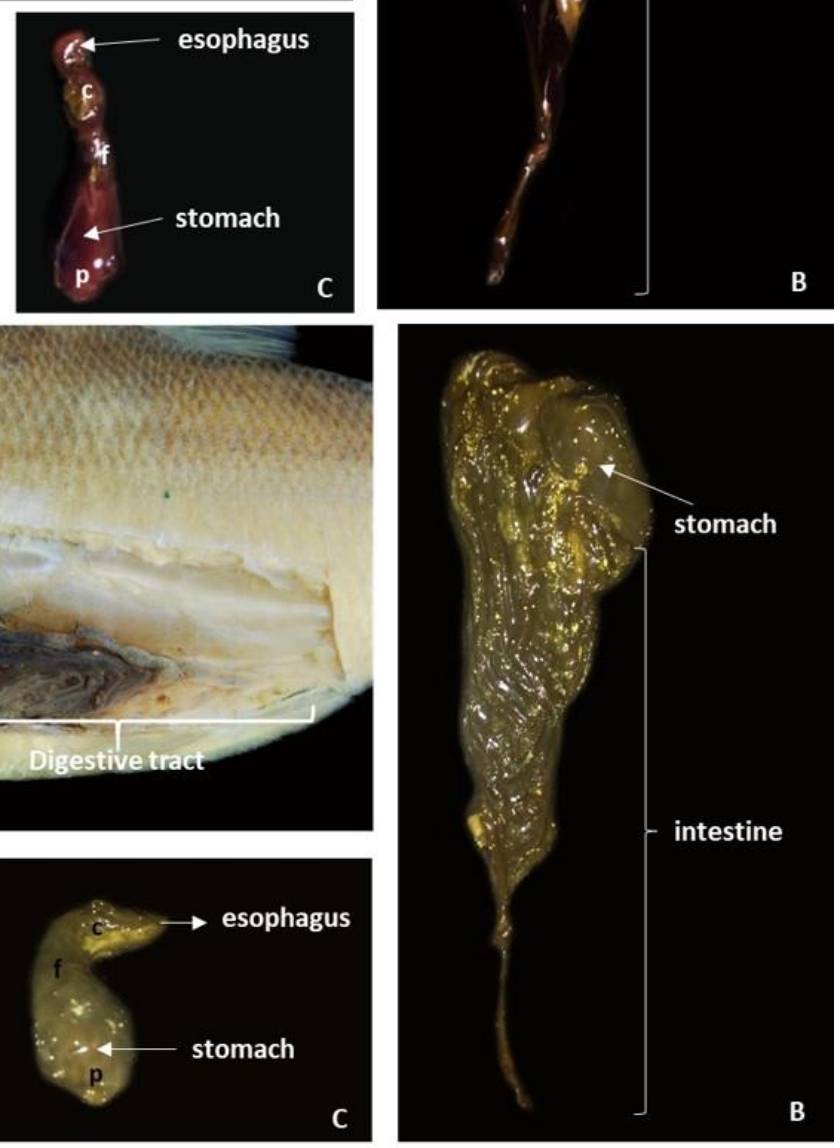

Figure S3. Images of the digestive tract of Psectrogaster rutiloides $(129 \mathrm{~mm})$ and Psectrogaster amazonica $(143 \mathrm{~mm})$. A: General view of the celom cavity indicating the position of the digestive tract. B: Digestive tract indicating stomach and long coiled intestine. C: Small, rounded stomach, of the fundic type with pyloric (p), fundic (f) and cardiac (c) regions and esophagus. 